\title{
ISOLATION OF SALMONELLA SPECIES FROM BUFFALO CALVES MEAT AND PRELIMINARY EVALUATION OF ITS IRRADIATED VACCINE
}

\author{
WAFAA S. MOHAMED and MADEHA A. IBRAHIM \\ National Centre for Radiation Research and Technology (NCRRT) - Atomic Energy Authority. Nasr City, P. Code 11762 - P. \\ O. Box: 7551, Cairo, Egypt. \\ E-Mail:wsmas1960@yahoo.com
}

\section{ABSTACT}

Received at: 21/10/2014

Accepted: 9/12/2014
The bacteriological examination of 200 meat samples obtained from diarrheic buffalo calves revealed that Salmonella isolates could be recovered with an incidence $2 \%$. Serological identification of Salmonella species by using O and $\mathrm{H}$ antisera revealed that the most common Salmonella serovars were Salmonella typhimurium followed by Salmonella dublin and Salmonella anatum with an incidence $1 \%, 0.5 \%$ and $0.5 \%$ respectively. Salmonella typhimurium is inactivated by $3 \mathrm{KGy}$ dose of irradiation of meat and also the isolated organism for preparation of the vaccine. The result of vaccination inoculation challenge studies revealed that the prepared Salmonella typhimurium vaccine was effective in protecting rabbits from salmonellosis.

Key words: Buffalo meat irradiation, Salmonella typhimurium vaccine.

\section{INTRODUCTION}

Salmonella is reported to be the most frequently diagnosed infectious cause of acute diarrhea in buffalo calves. Mortality from acute salmonellosis in calves may be as high as $60 \%$; so it is necessary to introduce urgent measures for control of the spread of Salmonella in calves (Gerdien et al., 2007).

Bovine salmonellosis is a worldwide bacterial disease causes great economic and public health problems. Salmonellosis is a zoonotic disease causing severe invasive infection in human and it causes economic and welfare losses in infected herds; as the disease causes fever and the meat of the affected animal will not be fit for human consumption (El- Safey, 2013). Salmonella is a group of bacteria that can cause a diarrhoeal illness in humans. Most infected persons develop diarrhoea, fever, and abdominal cramps 6 to $72 \mathrm{~h}$ after infection. The illness usually lasts 4 to 7 days. However, too many people continue to get sick and die from eating contaminated food. The disease in calves usually occur between two to six weeks of age, although animals may become infected after birth, or with S.dublin may be born infected.

In Egypt, Salmonella typhimurium was recovered with an incidence ranging from 8.4\%- $19.0 \%$ from calves. (Galal et al., 2008). Protection of animals from Salmonella should have a top priority, so Salmonella reduction plan which depends on rapid diagnosis and vaccination must be established (Nagy et al., 2001).

Ionizing radiation is able to inactivate food borne pathogens on a variety of food products and can serve as a final critical control point to ensure the microbiological safety of foods (Kundu et al., 2 014).

Vaccines made with bacteria killed by gamma radiation, rather than by standard methods of heat or chemical inactivation, may be more effective, also may not need to be kept cold till the time of use; an advantage in setting where refrigerated vaccines are impractical or impossible (Raz et al., 2006). Irradiation destroys the DNA, making the bacteria unable to replicate so it cannot establish an infection, but some residual metabolic activity may survive, so the irradiated bacteria can still find its natural target in the host. (Chaander et al., 2007).

Aim of the work: Isolation and identification of Salmonella typhimurium from the meat of diarrheic buffalo calves and preparation of vaccine from it by using gamma radiation.

\section{MATERIALS and METHODS}

Samples: A total of 200 meat samples obtained from diarrheic dead buffalo calves, were examined for the presence of Salmonella typhimurium at El-Dakahlia Governorate, the samples were sent with a minimum delay to the laboratory (Department of Radiation 
Health Researches) for investigation under aseptic precautions and sent to the lab in an ice box.

Bacteriological examination: preparation of food homogenate, dilution and spreading were performed according to ICMSF (1978) and Swanson et al. (1992)

Isolation of Salmonella (Vassiliadis et al., 1978): A quantity of $25 \mathrm{gm}$ of sample was pre-enriched in 225 $\mathrm{ml}$ buffered peptone water $1 \%$ and was incubated at $37{ }^{\circ} \mathrm{C}$ for $24 \mathrm{~h}$. Then one $\mathrm{ml}$ of pre-enriched broth was transferred into a tube containing $10 \mathrm{ml}$ of Rappaports Vassiliadis (RV) (Oxoid CM669) broth and incubated at $40^{\circ} \mathrm{C}$ for $48 \mathrm{~h}$. A loopful from the enriched broth was streaked on Xylose-Lysine Desoxycholate (XLD) agar selective medium (Oxoid) and MacConkey agar plates (Oxoid No3); two plates for each sample. The plates were incubated at $37{ }^{\circ} \mathrm{C}$ for $24 \mathrm{~h}$. On XLD the red colonies with or without black centres were suspected to be Salmonella, so did clear transparent colonies on MacConkey agar. Suspected colonies were cultured on nutrient agar slope for further identification.

Identification of the isolated Salmonella: a) Morphological examination: Films were made from the pure culture of the isolated organism. Stained with Gram's stain and examined under the oil emersion lens; Salmonella are Gram-negative short bacilli. b) Biochemical reaction: Suspected isolates were biochemically identified to be Salmonella using biochemical reactions (TSI), Indole production, Voges-Proskauer and Sugar fermentation. These tests were performed in the serology unit of the Animal Research Institute. c) Serological identification of Salmonella species: Determination of $\mathrm{O}$ (somatic antigens) Separate $\mathrm{O}$ antisera (Behringwerke AG Diagnostica) were applied to determine the group of the Salmonella isolates. Determination of $\mathrm{H}$ (flagellar antigens) Polyvalent $\mathrm{H}$ antisera (Behringwerke AG Diagnostica) for both phase 1 and phase 2 were tried in order to determine the complete antigenic formula of the isolates. For these purpose rapid diagnostic $\mathrm{H}$ antisera, sets (Behringwerke AG Diagnostica) were used.

From the biochemical reactions, the suspected colonies were subjected to serological identification according to Kauffman white schemes (Kauffman, 1973). The isolates were sub- cultured on nutrient agar plates for $24 \mathrm{~h}$ at $37{ }^{\circ} \mathrm{C}$ for application of slide agglutination technique. Two separate drops from microbial suspension in physiological saline were applied on clean glass slide. A drop of each of separates $\mathrm{O}$ and $\mathrm{H}$ Salmonella antigens standard loop were added and mixed to bring the microorganisms in close contact with antisera. Positive agglutination occurred within a minute and could be easily seen with the naked eye. A delayed or partial agglutination was considered as negative or flakes.

Preparation of gamma -irradiated S. typhimurium vaccine (Xu et al., 2007): 1- Preparation of dense cultures of Salmonella typhimurium: Salmonella typhimurium recovered from the meat of diarrheic buffalo calves was used to prepare inactive whole cell vaccine. An overnight culture of $S$. typhimurium grown in shaker water bath at $200 \mathrm{rpm}$ in $200 \mathrm{ml}$ of Luria broth. The broth culture was centrifuged at $9000 \mathrm{rpm}$ for $15 \mathrm{~min}$. at room temperature and pellet washed three times with sterile phosphate buffered saline (PBS). The final pellet was resuspended in 50 $\mathrm{ml}$ sterile PBS equivalent to a bacterial count of 1.0 $\times 10{ }^{10} \mathrm{CFU} / \mathrm{ml}$ and diluted by using McFrland tube to $9 \times 10^{8} \mathrm{CFU} / \mathrm{ml}$. The count was confirmed by using drop plate technique (Fierer and Guiney, 2001).

2- Irradiation process: Several trials were carried out to detect the optimum dose of gamma radiation required for complete inactivation of Salmonella typhimurium. The microorganism was dispensed into three bottles. The bottles were exposed to gamma rays emitted from cobalt 60 source at room temperature; at a dose rate of $5.6 \mathrm{KGy} / \mathrm{hr}$. The irradiation process was carried out using the facilities of the National Center for radiation Research and Technology, Egypt. After treatment with gamma radiation at doses of $3,3.5$ and $4 \mathrm{kGy}$, one loopful from each bottle was cultivated on nutrient agar to determine the optimal inactivation dose.

Quality control of the prepared vaccine: The S.typhimurium was inactivated by $3 \mathrm{KGy}$ dose of gamma irradiation. The vaccine was prepared by mixing $9 \times 10^{8} \mathrm{CFU} / \mathrm{ml}$ of irradiated Salmonella combined with Freund's incomplete oil adjuvant. The prepared vaccine was tested for inactivation, purity, sterility and safety according to the standard international protocols described by British Veterinary Codex (1970) and code of the American Federal Regulation (1985).

Purity test: This test was done before gamma inactivation of the used $S$. typhimurium. It was applied to confirm that the used broth culture of $S$. typhimurium did not contain any contamination by other organisms before inactivation. Such purity was detected by inoculation of the broth culture onto nutrient agar and incubation at $37^{\circ} \mathrm{C}$ for 48 hours. Pure colonies of S.typhimurium were observed.

Completion of inactivation for S.typhimurium: In assurance that the used $S$. typhimurium was completely inactivated, nutrient agar plates were inoculated with the irradiated vaccine. After 24-48 hours post inoculation, the detection of complete inactivation was recorded when no visible growth was reported. 
Sterility test: The prepared vaccine was confirmed to be free from any contaminants by inoculation of Thioglycollate broth, nutrient agar and MacConkey agar media and incubation at $37^{\circ} \mathrm{C}$ for 72 hours. Also inoculation was done on Sabouraud dextrose agar plates that were incubated at $25^{\circ} \mathrm{C}$ for 7 days. Inoculation was made also on Mycoplasma broth and agar plates and incubated at $37^{\circ} \mathrm{C}$ for 72 hours and 14 days in $5 \% \mathrm{CO}_{2}$ simultaneously.

Challenge procedure after vaccination of rabbits with the prepared vaccine: Three weeks after boostering, 25 rabbits (A: unvaccinated non immunized control group, B: subcutaneously vaccinated rabbits group with $1 \mathrm{ml}, \mathrm{C}$ : subcutaneously vaccinated rabbits group with $1.5 \mathrm{ml}$, D: intramuscularly vaccinated rabbits group with $1 \mathrm{ml}$, and E: intramuscularly vaccinated rabbits group with $1.5 \mathrm{ml})$.
Mortality rate, lesion/ scores: Following challenge, all rabbits were kept under observation daily for 23 days and the mortality rates were recorded. All dead rabbits and some survivors were subjected to postmortem examination for any characteristic lesions. Re-isolation: Re-isolation of S. typhimurium from meat samples of diarrheic immunized \& non immunized rabbits after challenge. (Serology unit, Animal Health Research Institute, Dokki, Giza.

\section{RESULTS}

Table 1: Showed that out of 200 meat samples. Four bacterial isolates were identified as Salmonella species with an incidence $2 \%$ identification of isolates was based on cultural, morphological biochemical character and serological examination.

Table 1: Incidence of Salmonella species recovered from meat of diarrheic calves:

\begin{tabular}{lcc}
\hline Salmonella isolates & \multicolumn{2}{c}{ Diseased calves } \\
\cline { 2 - 3 } & No. of positive samples & \% of positive samples \\
\hline S.typhimurium & 2 & 1 \\
\hline S. dublin & 1 & 0.5 \\
\hline S. anatum & 1 & 0.5 \\
\hline Total & 4 & 2 \\
\hline
\end{tabular}

*The percentage was calculated according to the total number of examined samples.

* Number of examined samples 200.

The culturally and biochemically identified Salmonella isolates were serotyped using slide agglutination test according to the Kauffmann-White scheme; the results recorded in Table (2) showed that two of Salmonella isolates 2 were S. typhimurium 1was S. dublin and 1 was S. anatum with an incidence $50 \%, 25 \%$ and $25 \%$ respectively.

Table 2: Antigenic structure of Salmonella serovars recovered from 200 meat samples of diarrheic calves:

\begin{tabular}{lcc}
\hline Salmonella serovars & \multicolumn{3}{c}{ Antigenic structure } \\
\cline { 2 - 3 } & $\mathrm{O}$ & $\mathrm{H}$ \\
\hline S. typhimurium & $1,4,5,12$ & 1,2 \\
\hline S. dublin & $1,9,12, \mathrm{Vi}$ & 0 \\
\hline S. anatum & 3,10 & 1,6 \\
\hline
\end{tabular}

Results of irradiation process: The proper dose of irradiation chosen for the inactivation of the vaccine was $3 \mathrm{KGy}$ for 10 minutes. Results of quality control tests proved that the gamma irradiated inactivated vaccine was confirmed to contain pure cultures of $S$. typhimurium (before gamma irradiation) and the inoculated nutrient agar plates were devoid of any bacterial growth. The sterility test revealed that the vaccine was free from bacterial and fungal contamination. Also the safety test indicated that the prepared irradiated vaccine was free from any contaminants (aerobic, anaerobic, fungi and Mycoplasma). As regards to safety tests, the prepared vaccines didn't show any abnormalities or adverse reactions during the seven successive days of inoculation of rabbits. While all rabbits were followed out and kept under observation up to the end of the experiment. 
Fig. (1) shows that S. typhimurium was re-isolated from the faecal samples of rabbits. S. typhimurium was shed till $7^{\text {th }}$ and $10^{\text {th }}$ days then stopped in the subcutaneously immunized rabbits with $1.5 \mathrm{ml}$ and $1 \mathrm{ml}$ respectively. While, in rabbits immunized intramuscularly with $1.5 \mathrm{ml} \& 1 \mathrm{ml}$. Salmonella still shed to the day 9 and 12 respectively. The control rabbits shed till the day 23 .

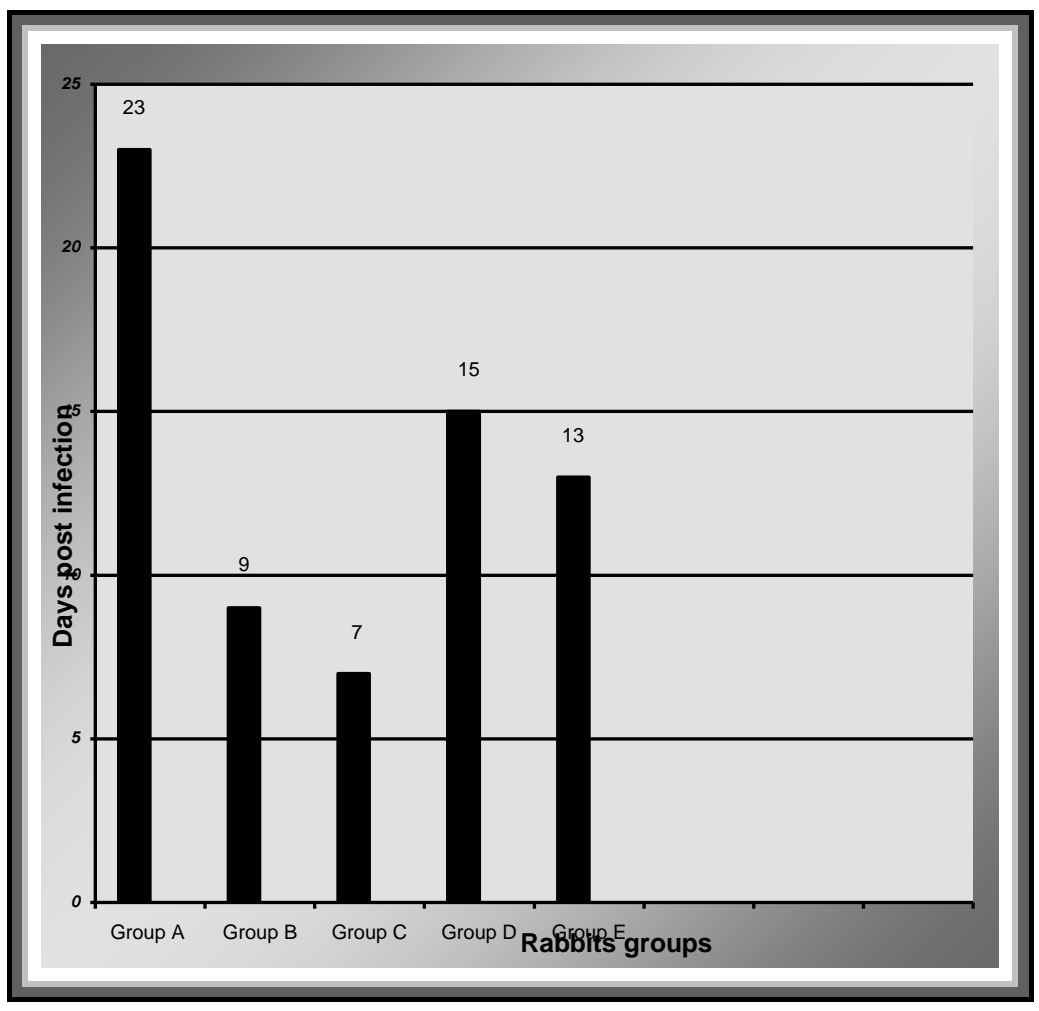

Fig. (1): Fecal shedding of $S$. typhimurium in challenged rabbits. Each group $=5$ rabbits.

Rabbits used in the experiment were checked before starting the experiment for $S$. typhimurium infection. Table (3) showed that four rabbits in control group (not vaccinated) died and one lived (20\%). One from group B (subcutaneously vaccinated rabbits group with $1 \mathrm{ml}$ ) died and no rabbits died from group $\mathrm{C}$ (subcutaneously vaccinated rabbits group with $1.5 \mathrm{ml}$ ) with protection rate of $100 \%$, two rabbits died from group D (intramuscularly vaccinated rabbits group with $1 \mathrm{ml}$ ); lived rabbits $3(60 \%)$. The last rabbit died with severe symptoms of diarrhoea from group E (intramuscularly vaccinated rabbits group with $1.5 \mathrm{ml}$ ); the survivals were $4(80 \%)$.

Table 3: Results of challenge test in rabbits vaccinated with irradiated S. typhimurium vaccine:

\begin{tabular}{lccc}
\hline Vaccinated group & Dead/total & Survival/total & Protection rate (\%) \\
\hline A & $4 / 5$ & $1 / 5$ & $20 \%$ \\
\hline B & $1 / 5$ & $4 / 5$ & $80 \%$ \\
\hline C & $0 / 5$ & $5 / 5$ & $100 \%$ \\
\hline D & $2 / 5$ & $3 / 5$ & $60 \%$ \\
\hline E & $1 / 5$ & $4 / 5$ & $80 \%$ \\
\hline
\end{tabular}

Each group $=5$ rabbits 


\section{DISCUSSION}

The incidence of Salmonella species recovered from meat samples: Three different Salmonella serovares were elucidated namely, $S$. typhimurium $S$. anatum and S. dublin with an incidence $1 \%, 0.5 \%$, $0.5 \%$ respectively. Nearly similar results were reported by Fosslar et al. (2004). While Oloya et al. (2007) recorded salmonellosis outbreaks with an incidence $45.7 \%$ and $55 \%$ respectively.

Serological identification of the isolates: The results recorded in Table (2) showed that two of Salmonella isolates 2 were $S$. typhimurium, 1 was $S$. dublin and 1 was $S$. anatum with an incidence $50 \%, 25 \%$ and 25 $\%$ respectively, similar results were reported by Veling et al. (2002).

Irradiation process: The proper dose of irradiation chosen for the inactivation of the vaccine was $3 \mathrm{KGy}$ as recorded by Alvarez et al. (2007); Sangyong et al. (2007) and Mohammed, 2010.

The vaccine was found to be safe and produced no clinical symptoms during the seven successive day's observation of the vaccinated rabbits.

Re-isolation: S. typhimurium was re-isolated from the fecal samples of rabbits. S. typhimurium was shed till $7^{\text {th }}$ and $10^{\text {th }}$ days then stopped in the subcutaneously immunized rabbits with $1.5 \mathrm{ml}$ and 1 $\mathrm{ml}$ respectively. While, in rabbits immunized intramuscularly with $1.5 \mathrm{ml} \& 1 \mathrm{ml}$ Salmonella still shed to the day 9 and 12 respectively. The control rabbits shed to the day 23 as shown in Fig. (1). The present results agree to large extent with the observation of (Jonson, 2009) who found that oral infection of rabbits with $S$. typhimurium led to death from 7 to 10 days with symptoms of diarrhea, enteritis and bronchopneumonia, while (Hanes et al., 2001) said that the rabbits began to recover from the infection on day 14 post infection as evidenced by weight gain and increased food consumption by day 23 post infection.

From data available in Table (3), it is evident that the protection percent of the subcutaneously vaccinated rabbits was higher than the protection percent of the intramuscularly vaccinated groups. Meanwhile 100\% of unvaccinated rabbits had severe lesions and the mortality percentage was $80 \%$, similar results were recorded by Nemer, 2010. All the inoculated rabbits with viable cells of $S$. typhimurium showed depression, ruffled fur, and anorexia, with yellowish diarrhoea after 2-3 days from infection. Slight watery discharge from eyes and nose was also observed in some rabbits. These results coincide with (Jang et al., 1999) who showed that a higher antibodies response was evoked by subcutaneous immunization because there was delay in absorbance to vaccine from subcutaneous than intramuscularly.

\section{CONCLUSION}

From results obtained in this study; $3 \mathrm{KGy}$ of gamma irradiation are enough to eradicate Salmonella typhimurium from meat and render the meat safe for consumption also it can be recommended that irradiated vaccine for S.typhimurium can be the vaccine of the future. Irradiated vaccine is inexpensive to produce, store, and transport without refrigeration.

\section{REFERENCES}

Alvarez, B.A.; Niemira, X.F. and Sommers, C.H. (2007): Modeling the Irradiation Followed by Heat Inactivation of Salmonella Inoculated in Liquid Whole Egg. J. Food Scie. 72(5).

American Fedral Regulation (1985): Published by the office of the Federal Register National Archives records service. General services administration USA.

British veterinary codex (1970): The pharmaceutical press, London.

Chander, R.; Nerkar, D.P.; Bandekar, J.R. and Lewis, N.F. (2007): Polyvalent radio vaccine against Salmonella. J. Food safety, 7(1): 31-34.

El-Safey, M.E. (2013): Incidence of Salmonella heidelberg in some Egyptian foods. Int. J. Microbiol., Immun. Res.1 (2): 016-025.

Fierer, J. and Guiney, D.G. (2001): Diverse virulence traits underlying different clinical outcomes of Salmonella infection. J. Clin. Invest. 107: 775-780.

Fossler, C.P.; Bender, J.B.; Warnick, L.D.; Rueqq, P.L.; Kaneene, J.B.; Wells, S.J.; Zwald, A.M.; Campbell, A.M.; Halbert, L.W. and Godden, S.M. (2004): Prevalence of Salmonella species on conventional and organic dairy farms. J.Amer. Vet. Med. Assoc., 15: 225(4): 567-73.

Galal, S.A.; Gomaa, A.M.; El-Gohary, H. and ElSawy, E. (2008): Screening of milk samples for Salmonella typhimurium in dairy herd using Enzyme Linked Immuno Sorbant Assay (ELISA). J. Egypt. Vet. Med. Assoc.: 68(3): 93-105.

Gerdien, V.S.; Klinkenberg, D.; Veling, J. and Stegeman, A. (2007): Transmission of Salmonella in dairy herds quantified in the endemic situation. Vet. Res. J. 38(6): 861-869.

Hanes, D.E.; Robl, M.G.; Schneider, C.M. and Burr, D.H. (2001): New Zealand white rabbit as a nonsurgical experimental model for salmonella enterica gastroenteritis. Infec. Immun.: 69(10): 523-526.

ICMSF "International Commission on Microbiological Specifications for Foods; Microorganisms in foods" (1978): I. Their 
significance and Methods of Enumeration "Enumeration of Salmonellae" (2nd-ed.), Toronto: University of Toronto Press PP. 162-172.

Jang, M.H.; Kim, S.Y.; Doh, H.J.; Ahn, J.S.; Ha, Y.J.; Chung, S.I. and Park, H.J. (1999): Induction of mucosal and systemic immune response by oral immunization with $\mathrm{H}$. pylori lysates encapsulated in poly (D, L-lactide-coglycolide) microparticles. Vaccine J.; 17: 607-616.

Johnson, I.M. (2009): Small Animal Zoonoses and Immunocompromised Pet Owners. Topics in Companion Anim. Med. J.: 24(4): 164-174.

Kauffman, F. (1973): Serological diagnosis of Salmonella species Kauffmann white scheme, Copenhagen, Denmark.

Kundu, D.; Gill, A.; Lui, C.; Goswami, N. and Holley, $R$. (2014): Use of low dose ebeam irradiation to reduce $E$. coli $0157: H 7$, non-O157 (VTEC) $E$. coli and Salmonella viability on meat surfaces. Meat Science: 96(1): 413-418.

Mohammed, W.E. (2010): Prevalence of Salmonella species in fishes and its control using irradiation. Egypt. J. rad. Sci. appl. 23(1): 105-111.

Nagy, B.; Bitay, Z.; Kovacs, S. and Norgradt, N. (2001): Prevention of Salmonellosis news opportunities in veterinary medicine. MagyarAllatorvosok lapsa, 123(11): 670-678.

Nemer, M. (2010): Evaluation of Irradiated Vaccine Prepared From Salmonella Typhimurium Isolated From Buffalo Calves. Ph.D. Vet. Sci. Fac. Vet. Med., Zagazig Univ.

Oloya, J.; Theis, M.; Doetkott, D.; Dyer, N.; Gibbs, P. and M.L. Khaitsa, M.L. (2007): Evaluation of Salmonella occurrence in domestic animals and humans in North Dakota (2000-2005). food borne pathogens and disease. 4(4) 450-456.

Raz, E.; Datta, S. and Fierer, J. (2006): Radiation killed bacteria vaccine induces broad immune response in mice. Am. J.; 56(7): 1123-1130.

Sangyong, L.; Jinwoo, J. and Dongho, K. (2007): The effect of gamma radiation on the expression of the virulence genes of Salmonella typhimurium and Vibrio spp. Rad. Phys. and chem.,76: 1763-1766.

Swanson, K.M.; Busta, F.; Peterson, E.H. and Johnson, M.G. (1992): Colony count methods. pp. 75-96 in Vanderzant, C. and O.Splittoesser (Eds). Compendium of Methods for Microbiological Examination of Foods. American Public Health Association. Washington, D.C.USA.

Vassiliadis, P.; Trichopoulos, D.; Pateraki, E. and Papaicono-Mou, N. (1978): Isolation of Salmonella from minced meat by the use of a new procedure of enrichment. Zentrablatt fur Bacteriologie, parasite Und Infectionskrankheiten Und Hygiene, B.166, 81.

Veling, J.; Barkema, HW.; Van der Schans, J.; Van Zijderveld, F. and Verhoeff, J. (2002): Herdlevel diagnosis for Salmonella enterica subsp. enterica serovar dublin infection in bovine dairy. Prev. Vet. Med. 14; 53 (1-2): 31-42.

Xu, Y.; Chen, A.; Fry, S.; Barrow, R.A.; Marshall, R.L. and Mukkur, T.K.S. (2007): Modulation of immune response in mice immunized with an inactivated Salmonella vaccine and gavaged with Andrographis Paniculata extract or andrographolide.

Immunopharmacol. 7: 515-523.

\section{عزل السالمونيلالا من لحم عجول الجاموس وتقييم اولى للقاح المشعع منها$$
\text { وفاء سبل محد ، مليحة عبل الحيث إبر/هيم }
$$ \\ E-Mail:wsmas1960@yahoo.com}

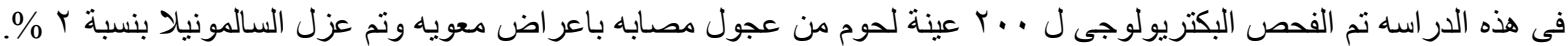

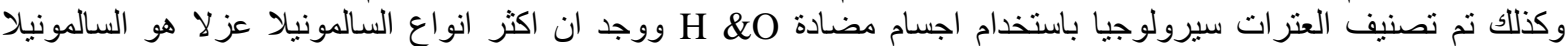

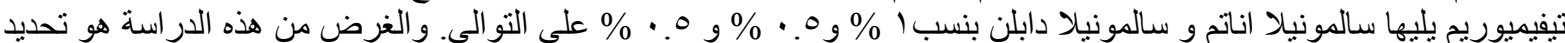

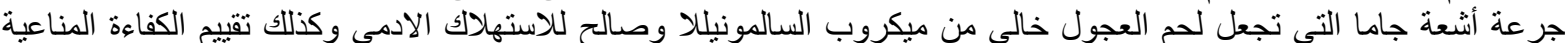

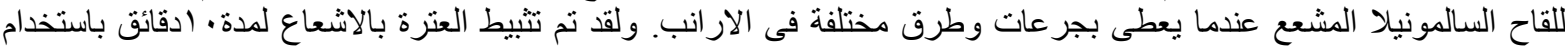

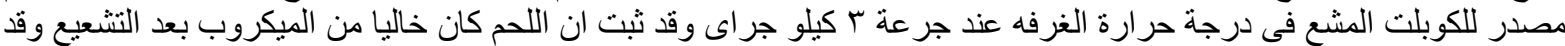

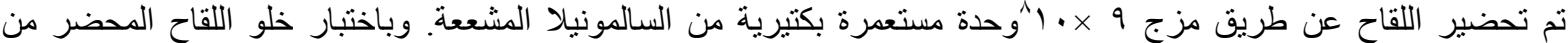

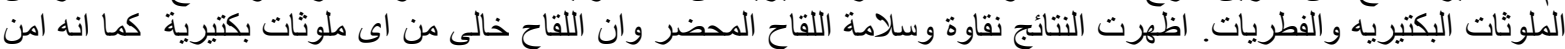

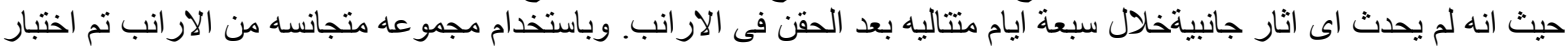

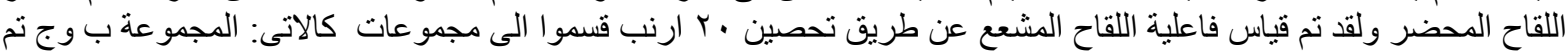

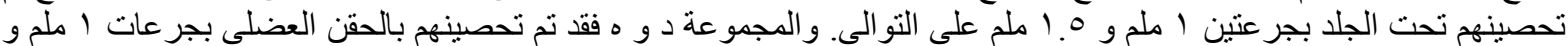

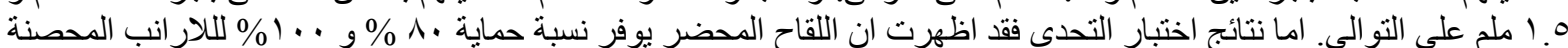

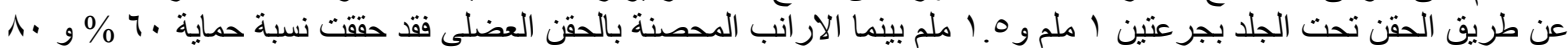

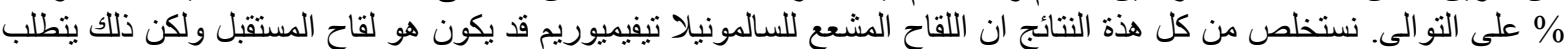
در اسات مكثفة لتقييم استجابتة المناعية. 